\title{
Not All Treaties Are Created Equal: The Effects of Treaty Changes on Legislative Efficiency in the EU
}

\author{
Jørgen Bølstad* James P. Cross ${ }^{\dagger}$
}

\begin{abstract}
One of the key motives behind recent reforms of the EU's legislative process has been to increase efficiency. This study examines whether the Amsterdam, Nice and Lisbon treaties have successfully increased the speed with which the EU creates new laws. An interrupted time series approach is utilized to detect the total effects of treaty change on the decision-making process. This study thus complements existing research on the effects of decision-making rules, by employing a design more robust to the challenge of endogeneity. The findings suggest that the Amsterdam treaty was very successful at increasing legislative efficiency. In contrast, the Nice treaty does not appear to have had a notable impact, and more interestingly, neither does the Lisbon treaty.
\end{abstract}

Keywords: Amsterdam treaty, Causal inference, Decision-making, Legislative Efficiency, Legislative procedures.

Corresponding author: Jørgen Bølstad, ARENA Centre for European Studies, University of Oslo, PO Box 1143 Blindern, Oslo, Norway. E-mail: jorgen.bolstad@arena.uio.no

Published as: Bølstad, Jørgen, and James P. Cross, "Not All Treaties Are Created Equal: The Effects of Treaty Changes on Legislative Efficiency in the EU", Journal of Common Market Studies, 54 (4): 793-808.

Acknowledgements: This paper was previously presented at the panel sessions on Causal inference and on European integration at the Annual Meeting of the Swiss Political Science Association, Bern, January 30-31, 2014, and at the Annual Retreat of the European Politics Group at the Center for Comparative and International Studies (CIS), ETH Zurich, January 27-29, 2014. We are especially grateful for comments by Stefanie Bailer, Tina Freyburg, Frank Schimmelfennig and Thomas Winzen.

*ARENA Centre for European Studies, University of Oslo, Norway.

${ }^{\dagger}$ University College Dublin, Ireland. 


\section{Introduction}

The European Union has gone through a series of treaty changes since its inception in 1958. The Single European Act, the Maastricht treaty, and the treaties of Amsterdam, Nice and most recently Lisbon have helped shape the EU into the highly complex institutional system that we see today. Of these treaties, Amsterdam, Nice and Lisbon were initiated to adapt the EU to the significant eastern enlargements starting in 2004. The two key aims of these treaties were to improve the democratic legitimacy of EU decision-making by increasing the involvement of the European Parliament (Lodge, 1994; Williams, 1990), and to streamline the decision-making process in order to avoid legislative gridlock (Garrett, 1992; Tsebelis and Kreppel, 1998). As a result, these treaty changes have had a profound effect on the character of the Union and the balance of power between the institutions and member states involved in the legislative process. Yet, the two main aims of the reforms are potentially conflicting, and it is unclear to what extent the reforms have been successful at achieving their aims.

This study therefore seeks to assess how successful the Amsterdam, Nice and Lisbon treaties have been at addressing the second rationale behind the reforms: increasing the efficiency of the decision-making process. It does so by considering how each treaty change has affected the EU's ability to legislate in a time-efficient manner. The dependent variable of interest is the time it takes the EU institutions to agree upon legislative proposals put forward by the Commission between 1995 and 2012. To test the hypothesis that treaty changes have increased the legislative efficiency of the EU, we use an interrupted time series (ITS) research design. In particular, we exploit the fact that a treaty change occurs at a particular point in time and is expected to have an immediate effect on legislative efficiency once it comes into force. This study thus complements existing studies on the effects of decision-making rules and reforms, by addressing key issues of causal inference in a direct and transparent way. The study also adds to the existing literature by estimating the total effect of each treaty change on decision-making efficiency across different legislative instruments. Our results suggest that the Amsterdam treaty was by far the most successful in increasing the legislative efficiency of the EU, while the Nice and Lisbon treaties have had little effect. In the conclusion, we elaborate on how these findings relate to the existing literature.

\section{Legislative procedures and efficiency}

Following the implementation of the Single European Act in 1987, a series of studies suggested that the EU faced significant difficulties in legislating due to Council inefficiencies (Scharpf, 
1988), and that the decision-making process was facing increasing legislative gridlock (Wessels, 1991). While these studies pointed to potential problems affecting the efficiency of the legislative process, they were not in a position to systematically and empirically assess the degree to which a slowdown in legislative efficiency was actually occurring over time. In response to this lack of systematic investigation, Schulz and König (2000) considered variation in the length of time between a proposal and the final decision outcome for a set of legislative decisions made between 1984 and 1994, conducting an event-history analysis.

One key finding of their study is that the use of qualified majority voting (QMV) in the Council decreases the time lag between a legislative proposal is made and a decision is reached. From a theoretical perspective, reducing the decision threshold from unanimity to QMV increases the number of potential winning coalitions capable of reaching a decision (Tsebelis, 2002). Put differently, it enables the exclusion of actors with extreme preferences who could veto unfavorable decisions under a more demanding unanimity rule. As a result, one would expect increased legislative efficiency under QMV, and many existing studies have reported findings that are consistent with this theoretical conjecture (König, 2007; Klüver and Sagarzazu, 2013; Golub, 2007; Golub and Steunenberg, 2007). ${ }^{1}$

Another key finding in the literature is that strengthening the role of the European Parliament (EP) increases the duration of the decision-making process (Schulz and König, 2000). ${ }^{2}$ The role of the EP in the decision-making process is determined by the legislative procedure in use. Under the consultation procedure, the EP is merely consulted, having very little formal power to block legislation that it does not approve of, while under the cooperation procedure, a proposal rejected by the EP can still be approved by a unanimous Council, thus still providing little impediment to making a fast decision. Finally, under the co-decision procedure, the approval of the $\mathrm{EP}$ is required for passing legislation, potentially representing a significant impediment to legislative efficiency (Crombez, 1996, 2000). The idea that EP-involvement decreases legislative efficiency has found support in a number of studies (Klüver and Sagarzazu, 2013; Golub, 2007; Golub and Steunenberg, 2007), although the effect may be modest (König, 2007).

The last key finding in this literature relates to informal modes of decision-making that have developed as a result of institutional changes embodied in the treaties (Farrell and Héritier, 2007, 2003). Most importantly, early agreements (EA) have been found to increase the speed

\footnotetext{
${ }^{1} \mathrm{~A}$ related literature (e.g Crombez and Hix, 2015; Junge et al., 2015) examines the volume of legislation, and finds for instance that QMV increases legislative activity.

${ }^{2}$ Other measures intended to promote democratic legitimacy, such as increased legislative transparency have also been found to conflict with legislative efficiency (see, e.g. Stasavage, 2004; Cross, 2013).
} 
of decision-making under co-decision. Early agreements allow proposals to be decided upon through informal agreement at either the first or early second reading stage of negotiations, allowing the Commission, Council, and EP to avoid many of the more formal procedural requirements associated with the later stages of co-decision. Such agreements usually emerge from informal trialogue negotiations between stakeholders that are convened to avoid negotiations proceeding to a second reading (Rasmussen and Reh, 2013). Accordingly, Toshkov and Rasmussen (2012) find that the first reading stage generally takes longer for early agreement proposals than for other proposals, but early agreement still significantly reduces the overall duration of the legislative process by avoiding further reading stages.

While all of the studies discussed above provide important insights into how decision-making rules affect decision-making efficiency, they have some limitations. These studies tend to focus on the formal and informal rules and procedures of decision-making, and usually attempt to identify their effects. To draw causal inferences, they generally rely on a 'selection on observables'-strategy, which may be problematic if unobserved confounders are indeed present, or the causal pathways are less straightforward than assumed (see e.g. Morgan and Winship, 2007). In particular, the existing studies tend to be silent about endogeneity: The possibility that the use of particular decision-making rules depends on the expected duration of proposals' legislative processing.

Such an endogenous relationship may arise in several ways, but most importantly, it may be brought about by the treaties governing the decision-making procedures. The fact that states during treaty negotiations are negotiating over which rules to apply, and that different rules are indeed used in different policy areas, suggests that these rules are far from randomly distributed across different areas. Indeed, it is very likely that the prescription of a given legislative procedure varies according to how hard it generally is to reach agreements in a given policy area. While, for instance, the efficiency-based rationale for introducing majority voting would be stronger where agreement is hard to reach, those who stand to be out-voted have strong incentives to avoid such procedures being applied. Accordingly, Moravcsik and Nicolaïdis (1999, p. 77) note regarding the negotiations for the Amsterdam treaty: 'While governments took rhetorical positions in favour of or opposed to the extension of QMV, in the fine print governments adopted finely differentiated policies in keeping with advancement of their substantive interests.' They further note: 'The ten major areas remaining under unanimity were all extremely sensitive for one or (more generally) a majority of Member States'. In other words, these were exactly the kind of areas where reaching an agreement would be likely to require a long and difficult negotiation. In short, procedures intended to speed up the legislative process, 
such as QMV, tend to be introduced in areas where decisions making would be relatively swift even without them - creating a major challenge for proper identification of their actual effects.

While these considerations by no means invalidate the very plausible key findings of the existing literature, they do illustrate the value of devising alternative research designs that dispense with the 'selection on observables'-assumption. This study seeks to do so by employing an interrupted time series analysis, complementing existing research in this area. In particular, the analysis will focus on estimating the overall effects of recent treaty changes on legislative efficiency. Such effects can only be loosely inferred from previous studies, as they have not been directly investigated, and our findings do indeed partially contradict some of the expectations derived from the literature.

\section{The treaties and their expected effects}

In this study, we consider the effects that the institutional changes embodied in the treaties of Amsterdam, Nice and Lisbon have had on the efficiency of the legislative process. As there is significant variation in the institutional changes that each of these treaty revisions entails, we will discuss each in turn, while deriving expectations regarding their effects. Before the introduction of the Amsterdam treaty, the Maastricht treaty was in force. This treaty, which went into force on November 1, 1993, had introduced the co-decision procedure that made the EP a co-legislator, and significantly extended the scope of the cooperation and assent procedures in EU decision-making. The Maastricht treaty also extended QMV within the Council to cover most decisions under the co-decision procedure and all decisions under the cooperation procedure.

Negotiations for the treaty of Amsterdam began in 1995 so as to amend the Maastricht treaty in order to prepare the EU for future enlargements and increase the democratic legitimacy of the decision-making process (Garrett, 1992; Tsebelis and Kreppel, 1998; Lodge, 1994; Williams, 1990). Its implications for decision-making efficiency mainly stem from three key features: (1) It significantly increased the use of co-decision in legislative decision-making, and thus strengthened the role of the EP in the negotiation process. Co-decision was extended to most of the existing EU competencies. This strengthening of the EP should in itself increase the duration of legislative negotiations, and thus have a negative effect on efficiency. However, (2) extension of co-decision generally went together with an extension of QMV in the Council, which is likely to have had a positive effect on efficiency. Furthermore, (3) the treaty also formalized the possibility of concluding negotiations in these areas through early agreements, 
which could significantly increase the speed of decision-making (Farrell and Héritier, 2004; Reh et al., 2011; Rasmussen and Reh, 2013). As the effect of EP-involvement may be modest (König, 2007), while the two other effects may be considerable, it is very likely that the treaty improved legislative efficiency overall. The Amsterdam treaty went into force on May 1, 1999.

The Nice treaty attempted to address some remaining concerns about vote weights in the Council that were not addressed by Amsterdam. It did so by establishing a double-majority requirement under QMV such that a qualified majority of both member states and votes cast were required to approve legislation. $62 \%$ of the total EU population also had to be represented by any decision, and member states could request verification that this requirement was met before a decision was approved. The treaty also involved a modest extension of QMV into new policy areas, and it increased the total number of seats in the EP once enlargement took place, overturning the cap established in the treaty of Amsterdam. In spite of these reforms, the Nice treaty was widely considered a failure for not going far enough in terms of the scope of the reforms it introduced to the voting procedures. More importantly, the treaty entailed few reforms that could improve legislative efficiency. In fact, while the modest extension of QMV might have had a positive impact, the double-majority requirement made it more demanding to reach decisions under QMV, leading to mixed expectations regarding the overall impact. After the conclusion of negotiations in February 2001, the Nice treaty went into force on February 1, 2003.

The Lisbon treaty finally addressed many of the concerns of those who argued that the previous two treaties failed to go sufficiently far. It did so by once again significantly extending the use of co-decision and QMV. Co-decision (since Lisbon referred to as the ordinary legislative procedure) was extended to most remaining policy areas and thus significantly empowered the EP. Similarly, QMV now plays a much more important role and applies to nearly all policy areas, including asylum, transport, energy, and the EU budget, but excluding foreign policy and tax issues. The treaty also simplified the double-majority requirement introduced by the Nice treaty: It abolished the use of weighted votes, while moderately tightening the requirements with regard to the number of member states in favor and the populations they represent. However, this adjustment of the QMV procedure only applies from November 1, 2014, and its effect will thus not be assessed here (in contrast to the extension of QMV to new policy areas, which took effect in 2009). ${ }^{3}$

Most observers considered the Lisbon treaty to be a success in terms of reforming the legislative decision-making process, as it concluded the reforms that were initialized when

\footnotetext{
${ }^{3}$ According to Thomson (2013), it is unlikely that this adjustment will have a notable effect.
} 
negotiations for Amsterdam were opened. ${ }^{4}$ In terms of legislative efficiency, the increased use of co-decision may have increased the length of legislative negotiations somewhat, while the considerable extension of QMV should have reduced it. In light of previous research, we might expect the latter effect to the stronger, which would lead us to expect a positive impact of the Lisbon treaty on legislative efficiency. The treaty entered into force on December 1, 2009.

\section{Data, methods and identification strategy}

In order to estimate the overall effects of the treaties on legislative efficiency, we exploit the time dimension of our data, using an interrupted time series (ITS) approach (see e.g. Morgan and Winship, 2007; McDowall et al., 1980). The general idea behind this approach is to model the dependent variable before and after the "treatment" occurs (i.e. a treaty entering into force) and estimating the effect of treatment as the discontinuity at the time of treatment. This estimate can be given a causal interpretation given the assumptions that the model is properly specified and that no other relevant change took place at the same time as the treatment (which we will discuss further below).

Our identification strategy has several advantages. First, it avoids the aforementioned endogeneity challenge facing existing analyses that focus on decision-making procedures. Looking at new treaties entering into force and using this as a treatment variable, we avoid this issue insofar as it applies to decision-making procedures and voting rules. More generally, this approach allows for fairly strong causal inferences, by greatly reducing the number of plausible confounders (as we discuss further in the section on internal validity). Furthermore, our design allows for a high level of transparency, as the effects we find are well-suited for graphical illustration. It also invites us to be explicit about the assumptions one inevitably must make in drawing causal inferences and that too often remain implicit in current research. Lastly, the approach of abstracting up to the level of treaties enables us to capture the complete effect of each treaty - effects that have not been examined in earlier research in such a holistic manner.

We use data from the European Union Policy-Making dataset (Häge, 2011), which has been extended by the current authors to cover proposals up to the year 2012, to test the expectations outlined in the previous section. The final dataset contains information scraped from the PreLex database on inter-institutional decision-making procedures. The proposals in the dataset were

\footnotetext{
${ }^{4}$ Apart from the mentioned reforms, the treaty also abolished the three-pillar system established in the Maastricht treaty and the previously separate pillars were consolidated so that the EU now represents a single legal entity.
} 
introduced by the Commission between 1975 and 2012 (as updated in the latest iteration of the study at the beginning of 2013). We start by considering a subset of these data relating to legislation decided upon between 1995-2012, as this time period broadly captures the time when the treaties of interest came into force. Within this dataset, we have information on the dates when the Commission makes a proposal and the dates when a final decision was reached (i.e. the date of formal adoption by the Council). We construct the dependent variable as the number of days between a proposal and decision. This variable is skewed, however, as some rare decisions take a very long time, producing a right-tailed distribution. In our graphs, we therefore transform this variable, calculating its natural logarithm (while our analyses use an appropriate link function).

Figure 1 thus shows the log of the dependent variable over time, using a quarterly time-scale. The treaties of interest are marked as dashed vertical lines. For decisions, the length of negotiation may seem to have dropped after the Amsterdam and Nice treaties, and the same could perhaps be said for regulations after the Amsterdam and Lisbon treaties. This might give an early indication that the treaties have had some effect, but assessing this issue properly requires a more finely grained analysis, taking into account any changes in the composition of legislation in terms of more and less sensitive policy areas, and this is what we aim to do below.

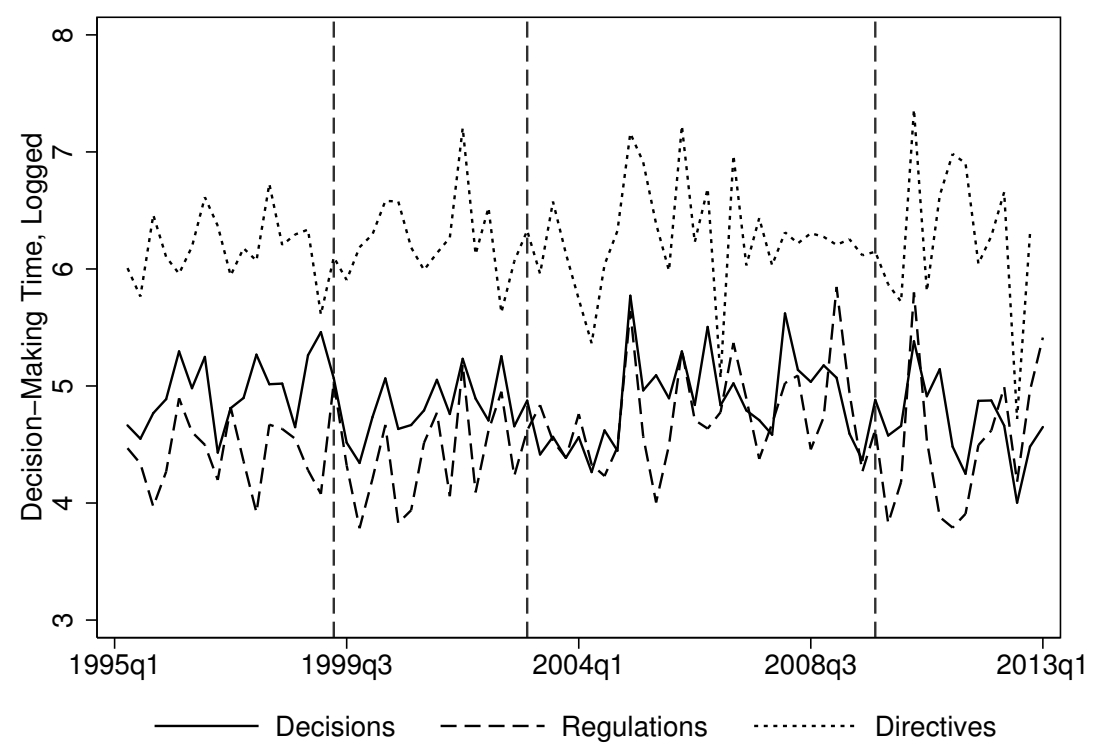

Figure 1: Speed of EU Decision-Making by Legal Instrument over Time.

Note: The dashed vertical lines represent the treaty changes investigated in this paper: Those agreed upon in Amsterdam, Nice and Lisbon, respectively.

We operate at two levels of analysis. The original data are at the level of proposals (as are our reported analyses). However, the ITS design relies crucially on the time dimension, and its validity is thus best assessed treating the data as a time series. This allows a transparent 
analysis, plotting relevant developments over time, and it further allows the use of time series diagnostics to assess whether the models are properly specified. For our analysis, we thus create a monthly time-scale, classifying decisions by their end-date (i.e. date of formal adoption by the Council). To obtain time series, we aggregate our variables (calculating the mean) over this time scale, and we then use the resulting series for plotting and for developing our models while employing time series diagnostics.

We analyze the impact of each treaty separately, using a set-up that is similar to a regression discontinuity design with local linear regressions on each side of the treatment threshold, as suggested by Imbens and Lemieux (2008), among others. Using smoother functions would also be an option, but mostly be a disadvantage, as we also implement the models at the level of proposals to include policy area controls. We thus prefer to fit linear trends before and after a treaty entered into force, selecting observations within a symmetrical window around this point in time. This window should be sufficiently narrow for this model to be appropriate, but wide enough to yield reliable estimates. Based on these considerations, we select windows covering two years on each side of the treatment (a total of 48 months). However, in the appendix, we also report results using alternative windows, and the key results of the analyses prove quite robust to the choice of window length.

For each treaty, we create a binary "treatment indicator" $(T)$ capturing whether the treaty was in force when a decision was made. ${ }^{5}$ For each analysis, we also center the time variable $(t)$ on the time of entry into force (i.e. $t=0$ when $T$ goes from 0 to 1 ), and include it in the analysis. We further interact $T$ and $t$, allowing the trend to change after treatment. Our analyses are thus based on the following general model:

$$
Y_{t}=\beta_{0}+\beta_{1} T_{t}+\beta_{2} t+\beta_{3} T_{t} t+\sum_{m=1}^{M} \beta_{m+3} X_{m t}+\varepsilon_{t}
$$

where $\beta$ is a vector of coefficients, $X$ is a vector of $M$ additional covariates, and $\varepsilon_{t}$ is an error term. With this specification, the centering of $t$ has the advantage that the coefficient on $T$ $\left(\beta_{1}\right)$ can be interpreted as the immediate effect of treatment (at $t=0$ ).

Before we consider implementing this model using the original unaggregated data, we implement it as an aggregate time series analysis. A key question that arises when dealing with time series data is how to specify the dynamics of the dependent variable. We control all

\footnotetext{
${ }^{5}$ Some decisions will, however, be in an intermediate category, being initiated before a treaty entered into force, but ending after. We still code these as treated, which is a conservative option, as a treaty's chance to influence these cases will be more limited.
} 
our models for seasonal patterns in the data, by including a set of dummy variables identifying monthly effects. We further test the models for first-order auto-regressive auto-correlation using the Breusch-Godfrey test, and for autoregressive conditional heteroskedasticity using Engle's Lagrange multiplier test (see e.g. Kennedy, 2008). The resulting time series diagnostics are generally unproblematic (and re-specifying the few models with potential issues to improve their diagnostics would not alter our findings). This means our models involve little dynamics and it is feasible to implement them at the level of individual proposals (rather than aggregating by month). The latter option is preferable as it retains more information, and allows for controls to be included at the lowest possible level of analysis. All of our final (reported) analyses are thus implemented at this level.

In order to model the count nature of the dependent variable, we use a negative binomial link function. The results generally indicate that the data are overdispersed, making this link function better suited than one representing a less flexible Poisson distribution. It should also be noted that the negative binomial function gives an analysis that closely resembles a survival analysis, and that our results are reported in terms of incidence rate ratios. Implementing a survival analysis would mainly provide alternative ways of describing the data and expressing the results, and thus offers little additional value compared to the reported models. As the main contribution of this paper is to provide an alternative research design to those implemented in existing studies, we rather focus on developing and explaining this design, with particular attention being paid to the time series aspects of the data and the issue of causal inference.

To further ensure that our estimates are not driven by changes in the substantive content of legislation enacted before and after a treaty change, we control for policy area in all our analyses, using a set of policy-area dummy variables to capture fixed effects. ${ }^{6}$ In particular, the issue we seek address is that the treaties extended the EU's legislative competence into new areas, and thus may have triggered new legislation in areas where negotiations tend to be easier or harder than normal. By controlling for policy area fixed effects, we estimate averages of the effects of treaty changes within each policy area, and thereby avoid this challenge. We return to the issue of internal validity after presenting the results of the analysis.

Lastly, to strengthen our analysis, we distinguish between policy areas that were more and less affected by a given treaty, by exploiting data on changes of legal bases for relevant proposals. A proposal's legal base, which is derived from the treaties, is associated with a particular set of decision rules, and if a proposal's legal base changes, so do potentially the rules used to decide

\footnotetext{
${ }^{6}$ Policy area is captured using the primarily responsible Commission Directorate-General (DG), with the assumption that each individual DG is responsible for a particular policy area.
} 
that on proposal. To construct a measure of legal base change at the level of policy areas, we first identify all proposals that were being processed when a given treaty entered into force. For each treaty, we then assess, by policy area, whether the relevant proposals had their legal base changed as indicated in PreLex. Based on this information we distinguish between three types of policy areas: (a) those that were highly affected (legal base changed for all proposals), (b) those that were less affected (legal base changed for some, but not all proposals), and (c) those that were unaffected (legal base did not change for any proposals). If a given treaty had an impact on legislative efficiency, we would generally expect to see the greatest effect in areas of type a, less effect in type b, and still less in type c. Admittedly, not all reforms would be recorded as a change in legal base, but the application of a new procedure in a given policy area would, and we thus find it instructive to make this further distinction.

\section{Analysis}

We start with the treaty of Amsterdam and its potential impact on negotiations regarding decisions. To assess our ITS model, we first implement it as a monthly time series analysis, illustrated in Figure 2. The plot shows the linear trend before and after the treaty entered into force, as well as a counterfactual line, extending the pre-treaty trend to the post-treaty period. The effect that our model is tailored to capture is the change taking place exactly at the time that the treaty entered into force (on May 1, 1999). The figure shows a clear discontinuity at this time, which supports the notion that the treaty had an immediate effect. As explained above, the size of this effect can best be assessed by implementing the model at the level of individual proposals, controlling for policy area to isolate the effect from any change in the volume of legislation in different areas. Model 1 in Table 1 thus implements the model as a negative binomial regression at the level of proposals. The reported incidence rate ratio (IRR) of .52 for the treatment variable implies that the average length on negotiation for decisions was approximately cut in half when the Amsterdam entered into force.

To strengthen this inference, Model 2 in Table 1 analyses a subset of proposals found in policy areas that were highly affected by the treaty, while Model 3 looks at those less affected (no policy area was entirely unaffected by this treaty). Corresponding figures can be found in the online appendix. If the treaty did indeed cause the effect found in Model 1 , we would expected a greater effect in Model 2 than in Model 3, and this is exactly what we find: The effect in Model 2 is notably stronger than in Model 1, while that in Model 3 is weaker, and not statistically significant. This increases our confidence in the conclusion that the Amsterdam 


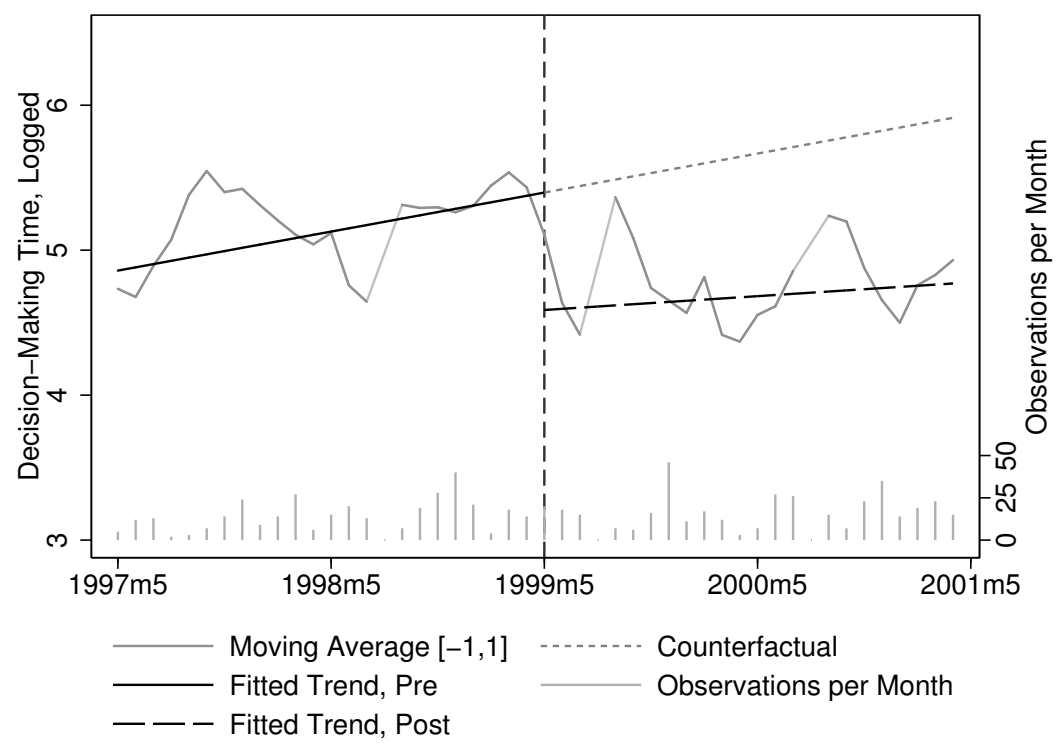

Figure 2: Overall Impact of the Amsterdam Treaty on Legislative Decisions.

Note: The fitted lines are weighted by the number of decisions contributing to each monthly average, which may give a slight deviation from the best unweighted linear fit. The moving average is plotted with a lighter shade of gray where it stretches across months with one or zero observations.

treaty reduced the length of negotiation for decisions.

Moving on to regulations, Model 4 in Table 1 is a general model, examining the impact of the Amsterdam treaty across all policy areas. The results point towards a considerable overall effect, reducing the length of negotiations by almost $40 \%$. As before, we seek to strengthen this inference by analyzing more and less affected policy areas separately. Model 5 thus examines highly affected areas, while Model 6 examines less affected areas, and these models are illustrated in Figure 3 and 4, respectively. The results are exactly as we would expect: The effect is stronger in highly affected areas, while there may not be any effect in less affected areas. (Unfortunately, the number of observations is lower in the highly affected areas, reducing the statistical power somewhat, but with a $t$-value of -1.87 , the two-tailed $p$-value is still close to .05 , at $.064-$ and the one-tailed value would of course be below this threshold.) These results thus increase our confidence in the conclusion that the treaty indeed reduced the length of negotiations for regulations.

Model 7 in Table 1 further analyzes directives across all policy areas. The IRR of .65 for the treatment variable implies a notable effect, but it is not strongly significant (with a t-value of -1.45$)$, so this result does not permit any firm conclusions. To finish our analysis of the Amsterdam treaty, Model 8 analyzes proposals relating to all legislative instruments and all policy areas (while including fixed effects for both). This model suggests that the Amsterdam treaty on average cut the length of legislative negotiations in half. 


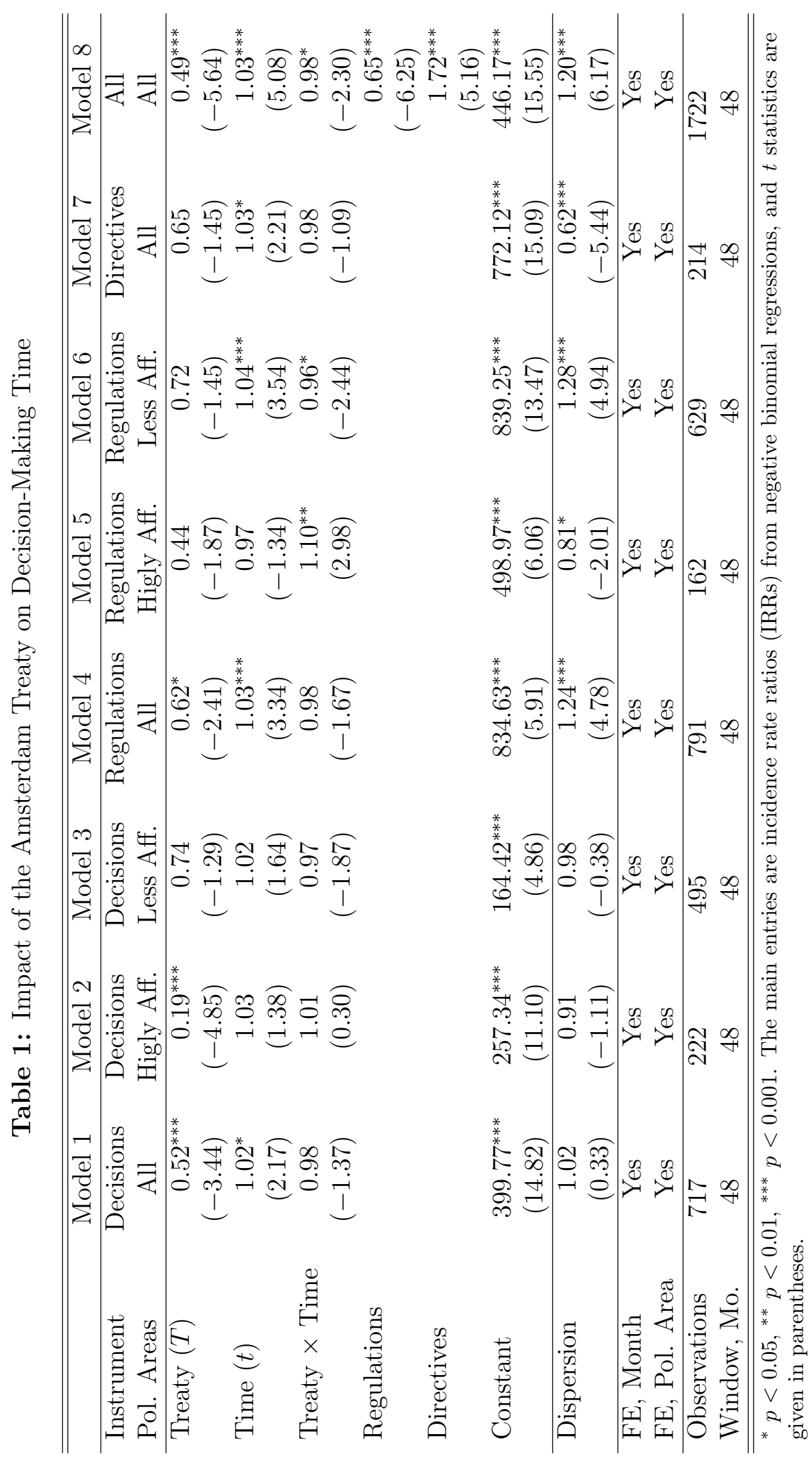




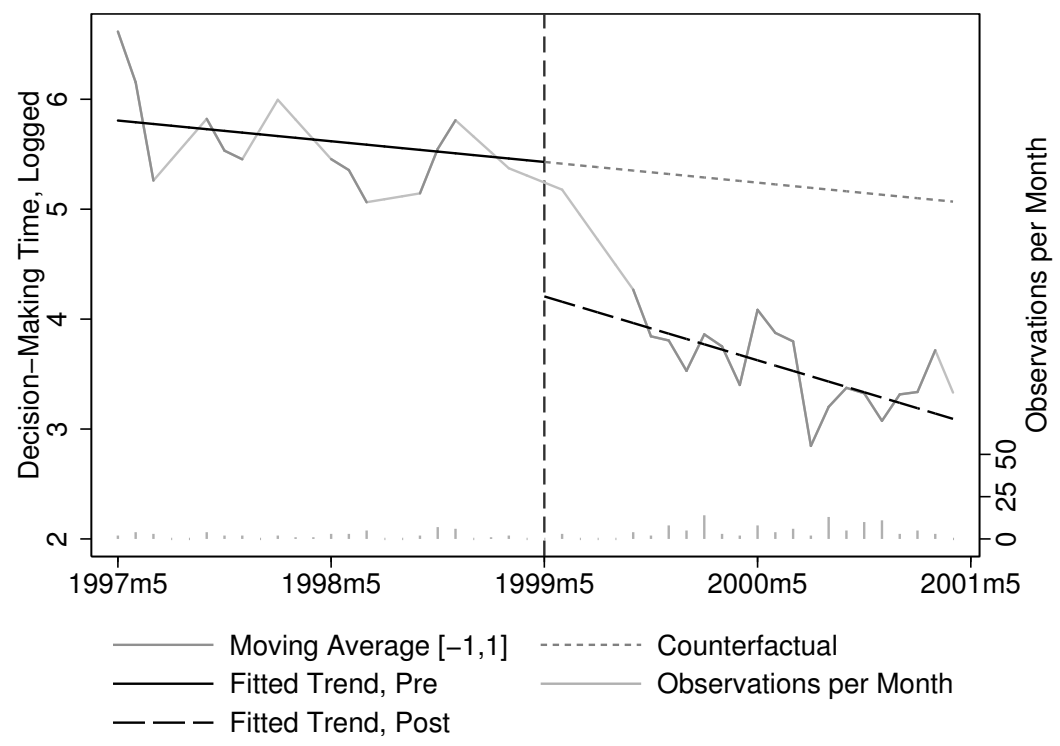

Figure 3: Impact of the Amsterdam Treaty on Regulations in Highly Affected Areas. Note: The fitted lines are weighted by the number of regulations contributing to each monthly average, which may give a slight deviation from the best unweighted linear fit. The moving average is plotted with a lighter shade of gray where it stretches across months with one or zero observations.

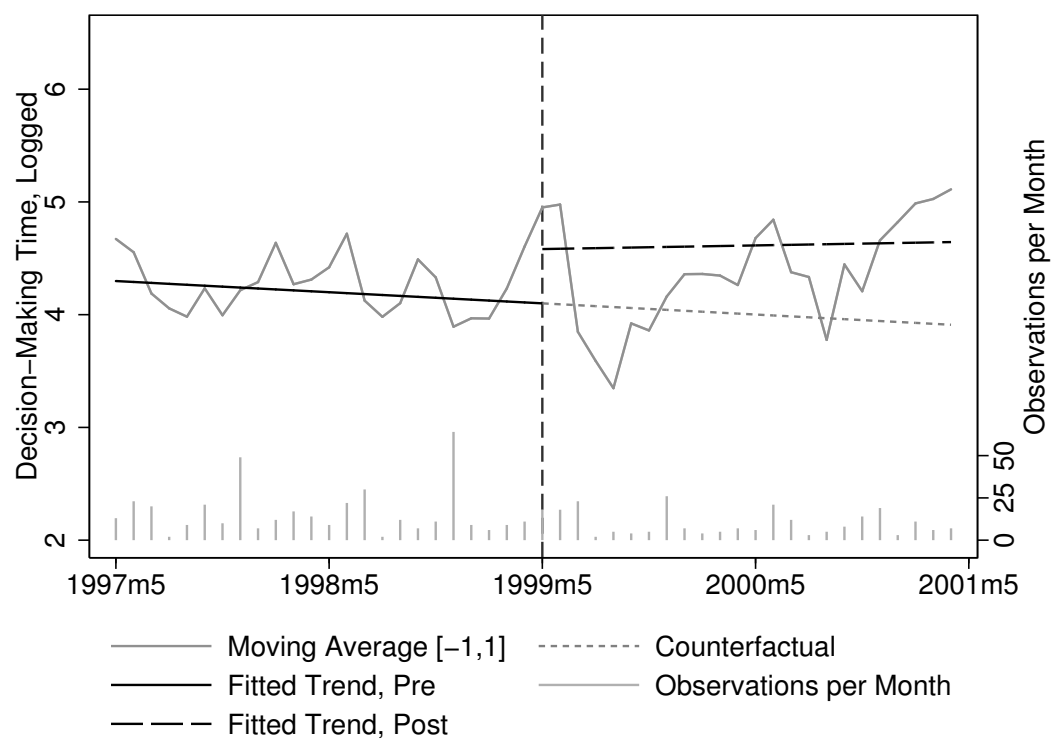

Figure 4: Impact of the Amsterdam Treaty on Regulations in Less Affected Areas.

Note: The fitted lines are weighted by the number of regulations contributing to each monthly average, which may give a slight deviation from the best unweighted linear fit. The moving average is plotted with a lighter shade of gray where it stretches across months with one or zero observations. 
Our analyses of the impacts of the Nice and Lisbon treaties are reported in full in the online appendix. The models are similar to those implemented for the Amsterdam treaty. However, the analyses detect do not detect any significant effect of either treaty on any type of legal instrument. In short, the models suggest that neither the Nice or Lisbon treaty significantly improved (nor worsened) legislative efficiency in the EU. ${ }^{7}$ We discuss this finding further in the conclusion.

\section{Internal validity}

The internal validity of our findings deserves some more discussion - in particular in the case of the Amsterdam treaty, which is where we see notable effects. The existing literature has identified a few explanations of negotiation length that we deliberately do not include in this analysis, as our study is designed to avoid the need for doing so (see e.g. Morgan and Winship, 2007). For instance, König (2007) introduces a divergence of preferences measure and finds that the larger the distance between the member states' positions, the longer the EU decision-making process takes. Similarly, Klüver and Sagarzazu (2013) find that in situations where the Commission, Council and Parliament are ideologically close to one another, decision-making speed is significantly reduced, and vice versa. Some readers might thus want to see analyses controlling for such variables.

We do not report such analyses for the following reasons. A key strength of the ITS and regression discontinuity $(\mathrm{RD})$ designs is their ability to reduce the range of plausible confounders in an analysis. A convincing explanation of the sharp decrease in the length of negotiations after May 1999 would have to show a similarly sharp change around that point in time. This rules out all but a few competing explanations. ${ }^{8}$ In addition, to further strengthen the design, we have distinguished between policy areas that were more and less affected by the Amsterdam

\footnotetext{
${ }^{7}$ It should be noted, however, that the Lisbon treaty would appear to have an effect on regulations, were it not for the policy area controls. In other words, it appears that the treaty triggered increased production of regulations in areas where processing of legislation is generally unproblematic.

${ }^{8}$ If we look at potential changes in the preferences of key institutions, the Prodi Commission took office on September 13, 1999, which may be somewhat late to plausibly explain the observed shift, but close enough to deserve consideration. However, the data reported by Klüver and Sagarzazu (2013) show that the new Commission's ideological position was very close to that of the preceding one, hardly offering any variation that could explain the results. The Fifth European Parliament (EP), which convened on July 20, 1999, could possibly be more relevant. However, the study of Klüver and Sagarzazu (2013) show that the ideological distance between the EP and the other institutions increased as a result of the 1999 election, which, if anything, should have increased the length of negotiations, and thus fails to explain the present findings.
} 
treaty, and the results are exactly as one would expect if the treaty did indeed have an effect. ${ }^{9}$ A plausible alternative explanation would therefore not only have to display a shift around May 1999, but also apply differently to exactly these policy areas, and this would seem to exclude most conceivable alternative explanations (including those mentioned above), leaving us quite confident that the Amsterdam treaty did indeed reduce the length of negotiations. ${ }^{10}$

\section{Discussion and conclusions}

Our study has an important limitation in that it does not seek to isolate the effects of specific institutional reforms, or to determine what part of the overall treaty effects is accounted for by a given rule change. This limitation stems from practical constraints as well as our aim of drawing reliable causal inferences: There exists no current dataset that would cover all relevant proposals and include information on Council voting rules and early agreements. Furthermore, we know that voting rules, early agreements, and legislative procedures covary, implying that the estimates would be biased if we considered only a subset of these intervening variables. Our focus is rather on the overall treaty effects, which allows us to draw more reliable conclusions.

Our results show that the Amsterdam, Nice and Lisbon treaties differ considerably in their impacts on the legislative efficiency of the EU. We find that the treaty of Amsterdam had a large effect, effectively cutting the length of negotiations in half. This effect is fairly consistent across legislative instruments, although it is clearer for legislative decisions and regulations than for directives. Furthermore, the effects we find are strongest exactly where we would expect them to be, namely in the policy areas with the most directly affected proposals. This increases our confidence in the conclusion that the Amsterdam treaty indeed did have a positive impact on legislative efficiency in the EU. ${ }^{11}$

\footnotetext{
${ }^{9}$ While EU enlargement has been found to slow down decision-making (e.g. Hertz and Leuffen, 2011; Cross and Bølstad, 2015), it should be noted that the enlargements rounds that took place closest to the Amsterdam treaty, effective from January 1, 1995, and May 1, 2004, hardly can explain the patters shown in the figures above.

${ }^{10}$ It could also be noted that if we control for variables such as proposal length (measured as the number of lines in a proposal and used as a proxy for legal complexity) or whether a proposal is amending existing legislation, this does not change our substantive results.

${ }^{11}$ However, as illustrated in Figure 1, the effect may not seem to have lasted. While our results suggest there was an immediate effect of the Amsterdam treaty, this effect becomes increasingly hard to distinguish from other influences as time passes. Interestingly, Figure 1 shows a sharp increase in decision-making time exactly when the 2004 Enlargement entered into force (in line with the expectations of many observers and policy-makers). This effect was also noted and analyzed in more detailed by Cross
} 
In contrast, we do not find any clear effects of the Nice and Lisbon treaties. In the case of the Nice treaty, this finding is in line with the observation that the treaty was largely unsuccessful in reforming the legislative process: It seems the commentators who argued that the Nice treaty failed to achieve its goals may have been right, at least in this regard. In the case of the Lisbon treaty, the null-finding is more interesting, as this treaty was a slightly watered-down version of the failed constitutional treaty, and has been seen as major reform of the EU. Its establishment of the ordinary legislative procedure and according expansion of QMV to most of the policy areas in which the EU has legislative competence is often cited as an important institutional development for the Union.

This invites the question of why the Lisbon treaty does not appear to have reduced the length of negotiations. A possible explanation would be that QMV has a weaker effect than it is generally thought to have - and there are indeed a couple of reasons why this may be so. One relates to the consensus norm characterizing Council negotiations (Héritier, 1999; Heisenberg, 2005): If negotiators seek unanimous agreement even when they could out-vote their opponents, the effect of formally increasing the use of QMV would be limited. Furthermore, as we explain above, QMV was first introduced in areas where agreement is generally easy to reach, and this would create a spurious relationship between the use of QMV and the length of negotiations. It thus appears likely that the effect of QMV has previously been overestimated, and we hope our study will trigger further studies on this topic.

and Bølstad (2015). Such influences appears to have brought average decision-making time back to previous levels or higher. It is worth recalling that countering the anticipated impact of enlargement was one of the main motives behind the treaty revisions, and it appears likely that legislative decision-making would have taken even longer if the Amsterdam treaty had not been in place before the enlargement. 


\section{References}

Crombez, C. (1996) 'Legislative procedures in the European Community'. British Journal of Political Science, Vol. 26, No. 02, pp. 199-228.

Crombez, C. (2000) 'Spatial models of logrolling in the European Union'. European Journal of Political Economy, Vol. 16, No. 4, pp. 707-737.

Crombez, C. and Hix, S. (2015) 'Legislative Activity and Gridlock in the European Union'. British Journal of Political Science, Vol. 45, pp. 477-499.

Cross, J. P. (2013) 'Striking a pose: transparency and position taking in the Council of the European Union'. European Journal of Political Research, Vol. 52, No. 3, pp. 291-315.

Cross, J. P. and Bølstad, J. (2015) 'Openness and Censorship in the EU: An Interrupted Time Series Analysis'. European Union Politics, Vol. 16, No. 2, pp. 216-240.

Farrell, H. and Héritier, A. (2003) 'Formal and informal institutions under codecision: continuous constitution-building in Europe'. Governance, Vol. 16, No. 4, pp. 577-600.

Farrell, H. and Héritier, A. (2004) 'Interorganizational Negotiation and Intraorganizational Power in Shared Decision Making: Early Agreements Under Codecision and Their Impact on the European Parliament and Council'. Comparative Political Studies, Vol. 37, No. 10, pp. $1184-1212$.

Farrell, H. and Héritier, A. (2007) 'Codecision and institutional change'. West European Politics, Vol. 30, No. 2, pp. 285-300.

Garrett, G. (1992) 'International cooperation and institutional choice: the European Community's internal market'. International Organization, Vol. 46, No. 2, pp. 533-560.

Golub, J. (2007) 'Survival Analysis and European Union Decision-making'. European Union Politics, Vol. 8, No. 2, pp. 155-179.

Golub, J. and Steunenberg, B. (2007) 'How Time Affects EU Decision-Making'. European Union Politics, Vol. 8, No. 4, pp. 555-566.

Häge, F. M. (2011) 'The European Union Policy-Making dataset'. European Union Politics, Vol. 12, No. 3, pp. 455-477. 
Heisenberg, D. (2005) 'The institution of 'consensus' in the European Union: Formal versus informal decision-making in the Council'. European Journal of Political Research, Vol. 44, No. 1, pp. 65-90.

Héritier, A. (1999) 'Elements of democratic legitimation in Europe: an alternative perspective'. Journal of European Public Policy, Vol. 6, No. 2, pp. 269-282.

Hertz, R. and Leuffen, D. (2011) 'Too big to run? Analysing the impact of enlargement on the speed of EU decision-making'. European Union Politics, Vol. 12, No. 2, pp. 193-215.

Imbens, G. W. and Lemieux, T. (2008) 'Regression discontinuity designs: A guide to practice'. Journal of econometrics, Vol. 142, No. 2, pp. 615-635.

Junge, D., König, T. and Luig, B. (2015) 'Legislative Gridlock and Bureaucratic Politics in the European Union'. British Journal of Political Science, Vol. 45, pp. 777-797.

Kennedy, P. (2008) A Guide to Econometrics (Oxford: Blackwell Publishing), 6th edn.

Klüver, H. and Sagarzazu, I. (2013) 'Ideological congruency and decision-making speed: The effect of partisanship across European Union institutions'. European Union Politics, Vol. 14, No. 3, pp. 388-407.

König, T. (2007) 'Divergence or convergence? From ever-growing to ever-slowing European legislative decision making'. European Journal of Political Research, Vol. 46, No. 3, pp. $417-444$.

Lodge, J. (1994) 'The European Parliament and the Authority-Democracy Crises'. The ANNALS of the American Academy of Political and Social Science, Vol. 531, No. 1, pp. 69-83.

McDowall, D., McCleary, R., Meidinger, E. E. and Hay, R. A. (1980) Interrupted time series analysis (Thousand Oaks, CA: Sage).

Moravcsik, A. and Nicolaïdis, K. (1999) 'Explaining the treaty of Amsterdam: Interests, influence, institutions'. Journal of Common Market Studies, Vol. 37, No. 1, pp. 59-85.

Morgan, S. L. and Winship, C. (2007) Counterfactuals and Causal Inference: Methods and Principles for Social Research (New York: Cambridge University Press). 
Rasmussen, A. and Reh, C. (2013) 'The consequences of concluding codecision early: trilogues and intra-institutional bargaining success'. Journal of European Public Policy, Vol. 20, No. 7, pp. 1006-1024.

Reh, C., Héritier, A., Bressanelli, E. and Koop, C. (2011) 'The Informal Politics of Legislation: Explaining Secluded Decision Making in the European Union'. Comparative Political Studies, Vol. 46, No. 9, pp. 1112-1142.

Scharpf, F. (1988) 'The joint-decision trap: lessons from German federalism and European integration'. Public administration, Vol. 66, No. 3, pp. 239-278.

Schulz, H. and König, T. (2000) 'Institutional reform and decision-making efficiency in the European Union'. American Journal of Political Science, Vol. 44, No. 4, pp. 653-666.

Stasavage, D. (2004) 'Open-Door or Closed-Door? Transparency in Domestic and International Bargaining'. International Organization, Vol. 58, No. 4, pp. 667-703.

Thomson, R. (2013) 'Double versus Triple Majorities: Will the New Voting Rules in the Council of the European Union Make a Difference?' West European Politics, Vol. 36, No. 6, pp. $1221-1238$.

Toshkov, D. and Rasmussen, A. (2012) 'Time to Decide: The effect of early agreements on legislative duration in the EU'. European Integration online Papers (EIoP), Vol. 16.

Tsebelis, G. (2002) Veto Players: How Political Institutions Work (Princeton: Princeton University Press).

Tsebelis, G. and Kreppel, A. (1998) 'The history of conditional agenda-setting in European institutions'. European Journal of Political Research, Vol. 33, No. 1, pp. 41-71.

Wessels, W. (1991) 'The EC Council: the Community's decision making center', in Keohane, R. O. and Hoffmann, S. (eds.) 'The New European Community: Decisionmaking and Institutional Change', (Boulder, Colorado: Westview Press), pp. 133-154.

Williams, S. (1990) 'Sovereignty and accountability in the European Community'. The Political Quarterly, Vol. 61, No. 3, pp. 299-317. 